\title{
Determination of an empirical model for calculating the strain of a dam in terms of hydrostatic thrust
}

\author{
[Julio Manuel de Luis Ruiz, Raúl Pereda García, Felipe Piña García, Rubén Pérez Álvarez]
}

\begin{abstract}
The deformational control of structures has its greatest exponent in the control of large dams, which depending on structural typology, can be subjected to movement generally based on the pressure that it suffers.

The designer usually calculates the theoretical displacements that the dam must suffer depending on the hydrostatic pressure, function of the thrust bearing, but it is also true that this calculation is theoretical and it is not usually adjusted to the real movements, due to the uncertainties that arise in the construction of any dam and make the original project have more or less significant changes in the final construction. In favour of the builder, it must be said that the actual displacements are usually lower than the theoretical ones.
\end{abstract}

The present research focuses on the determination of an empirical model that allows calculating the deformation based on practical observations of a direct pendulum over 14 years, which determines the displacement and the pressure experienced by the dam represented by the height of water contained, by means of a polynomial adjustment. This empirical model is tested and then validated with observations over the following year and, although it is only valid for the dam where the trial (La Cohilla Dam) is made, the methodology is applicable to any other structure.

Keywords - Auscultation, geometric control, pendulum, hydrostatic thrust.

\section{Introduction}

Current legislation in Spain requires companies that own large dams to undergo regular geometric control on dams of their property to ensure a proper structural behaviour.

Julio Manuel de Luis Ruiz (ORCID ID 0000-0001-6633-3690)

Polytecnhic School of Mining and Energy Engineering / University of Cantabria

Spain

\section{Raúl Pereda García}

School of Civil Engineering / University of Cantabria Spain

Felipe Piña García

School of Civil Engineering / University of Cantabria Spain

\section{Rubén Pérez Álvarez}

Polytechnic School of Mining and Energy Engineering / University of Cantabria

Spain
For this purpose, pendulums that record the movements to which the dams are subjected are installed in these structures. Depending on the structural typology, those pendulums must be limited within certain values which are frequently predefined by designers and determine the theoretical range of motion. The range thus established does not usually match the actual value, due to the uncertainties that arise during the construction of the dam itself and impede an exact fit between structure and project. Therefore, it is necessary to set the actual framework of movement once the structure is in operation, which is usually held in terms of the observations taken with these pendulums.

\section{Instruments and Materials}

All the data used to conduct this research correspond to those obtained from the observations that were carried out in a large dam called La Cohilla, which is located in Cantabria, Spain. The following figure shows the dimensions of this structure, consisting of an arch dam with an approximate size of 110 meters in height and 240 in width.

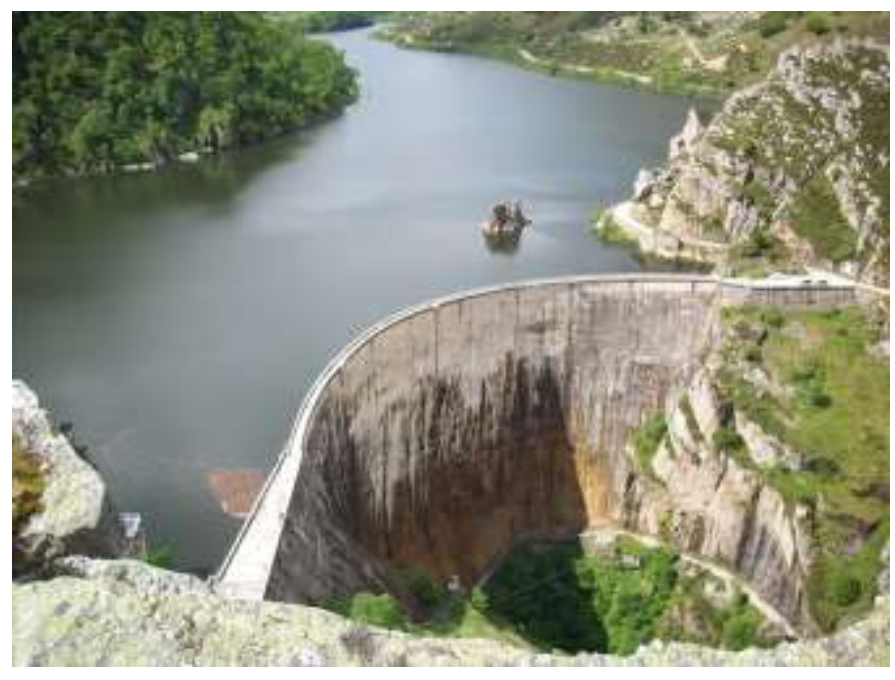

Figure 1. La Cohilla Dam (Cantabria/Spain).

The pendulum basically consists of a very long wire with a mass suspended at its lower end. When the gravitational field operates on the mass, gravity force that tightens the wire and keeps it within the directions of the field lines (vertical) is produced. In the case of La Cohilla Dam, the pendulum is a direct one, and it is located at the center of the dam, on its top, remaining the part that is outside the structure protected by a pipe. The part that is outside of the structure remains protected by a pipe 
La Cohilla Dam is a reservoir with a capacity of 10 cubic hectometers that constitutes the header-dam of a hydroelectric plant called "Saltos del Nansa", which also owns three other dams located downstream River Nansa for its supply.

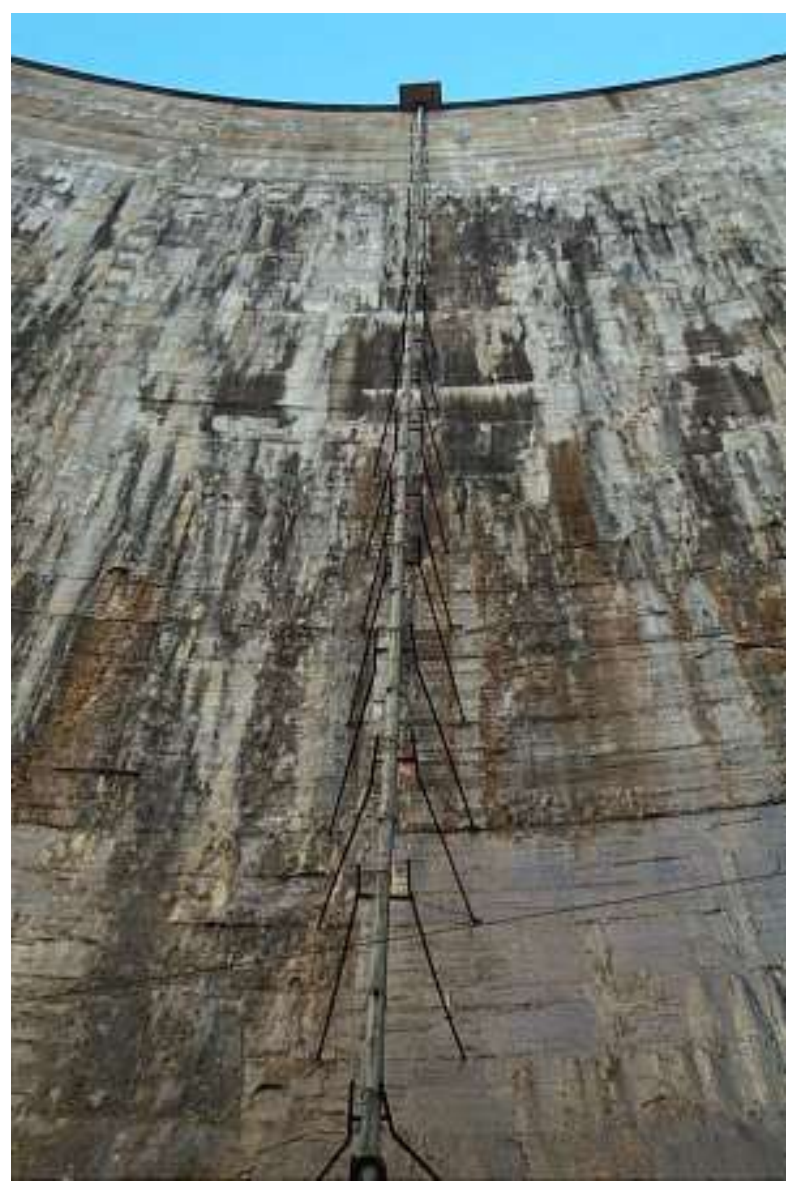

Figure 2. Pendulum in La Cohilla Dam.

Since the pendulum is located on top of the dam, any movement that may occur at its upper end is transmited to the lower one, where the reading micrometer is located.

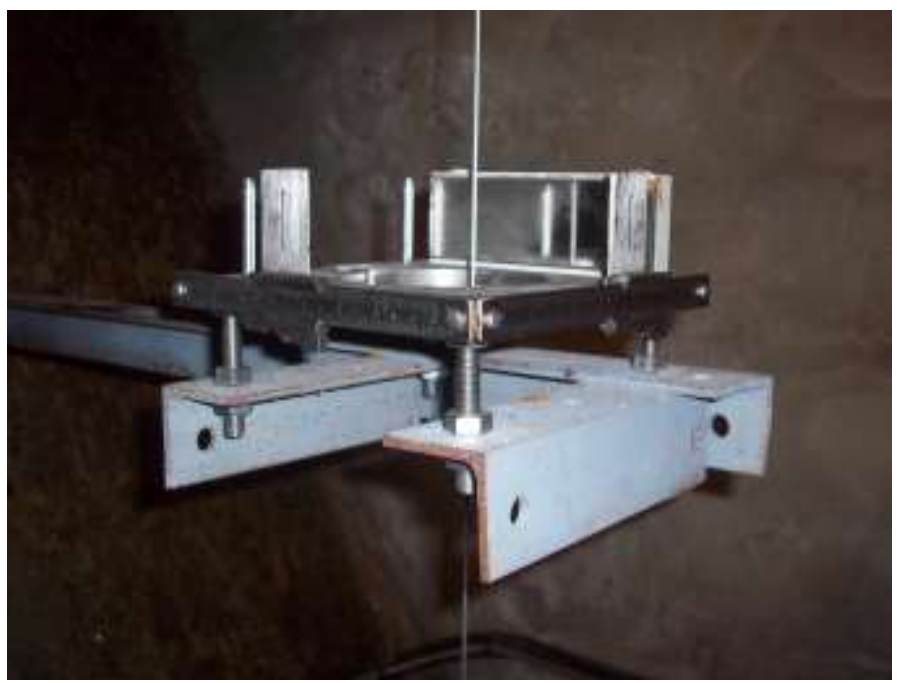

Figure 3. Micrometer of the pendulum in La Cohilla Dam.
Although the pendulum is characterized by determining the point position continuously, records are registered, as reading is not automated, so the person in charge of the dam must go there and access to the pendulum location, which is not always possible due to the adverse weather conditions prevailing in the area, specially in winter. Usually observed variables are shown in the table below.

TABLE I. OBSERVABLES OF PENDULUM.

\begin{tabular}{|c|c|c|c|c|}
\hline Record & Date & $\begin{array}{c}\text { Height } \\
(\mathbf{m})\end{array}$ & $\begin{array}{c}\text { Coord_X } \\
(\mathbf{m m})\end{array}$ & $\begin{array}{c}\text { Coord_Y } \\
(\mathbf{m m})\end{array}$ \\
\hline 3777 & 04.01 .00 & 58.90 & 8.16 & 11.84 \\
\hline 3778 & 11.01 .00 & 53.11 & 7.57 & 11.10 \\
\hline 3779 & 14.01 .00 & 49.85 & 7.13 & 10.69 \\
\hline 3780 & 18.01 .00 & 44.80 & 6.09 & 9.66 \\
\hline 3781 & 21.01 .00 & 40.15 & 5.63 & 9.19 \\
\hline 3782 & 28.01 .00 & 31.56 & 4.19 & 7.54 \\
\hline$\ldots$. & $\ldots$. & $\ldots$. & $\ldots$. & $\ldots$. \\
\hline
\end{tabular}

Record includes a serial number that indicates the order observation. Date is specified in "day.month.year" format. Height reflects the level reached by stored water, and hence the hydrostatic thrust. $\mathrm{X}$ and $\mathrm{Y}$ coordinates are referred to a local system set when the pendulum was instaled in the dam, which is characterized by the following geometry.

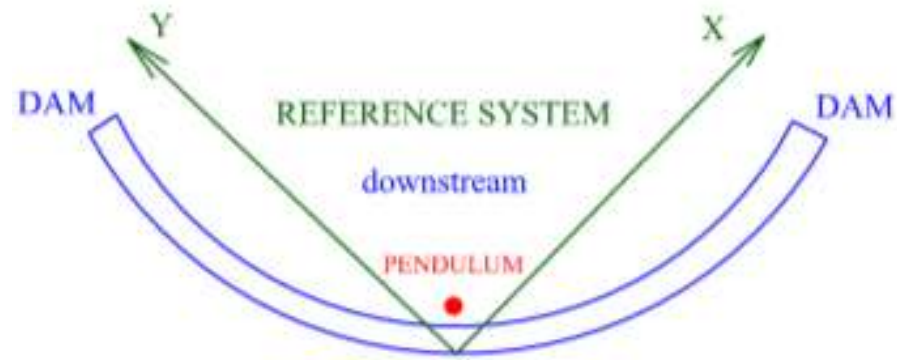

Figure 4. Pendulum reference system in La Cohilla Dam.

\section{Methodology}

In order to guarantee a sufficiently representative sample for the conduction of the research, data observed during 14 years (from January 1st, 2000 to December 31st, 2013) are processed, and those obtained in 2014 are left to contrast results obtained.

As a first step, coordinates are expressed as coordinate differences with respect to a certain position, which allows working with displacements instead of coordinates and permits the development of a mathematical adjustment. To ease the interpretation of that displacement, the rearmost 
position of the dam, which is obviously characterized by the lowest hydrostatic thrust value, is adopted as position Po. Being field-observables verified, Record 4903, registered on September $12^{\text {th }}, 2012$ was identified as the rearmost position in the data set [1.27/4.50], due to a fault in the drain at the bottom that left the height of the water stored in 9.02 meters.

Using the following expression:

$$
\text { Displ. }=\sqrt{(X-1,27)^{2}+(Y-4,50)^{2}}
$$

Displacement is obtained with respect to this initial position, which along with hydrostatic thrust (represented by the height of stored water and to the date on which the observation is made) comprise the data aimed to have adjusted by means of polynomial fit

TABLE II. TRANSFORMATION OF DISPLACEMENTS.

\begin{tabular}{|c|c|c|c|}
\hline Record & Date & Height (m) & $\begin{array}{c}\text { Displacement } \\
(\mathbf{m m})\end{array}$ \\
\hline 3777 & 04.01 .00 & 58.90 & 10.07 \\
\hline 3778 & 11.01 .00 & 53.11 & 9.12 \\
\hline 3779 & 14.01 .00 & 49.85 & 8.52 \\
\hline 3780 & 18.01 .00 & 44.80 & 7.06 \\
\hline 3781 & 21.01 .00 & 40.15 & 6.40 \\
\hline 3782 & 28.01 .00 & 31.56 & 4.22 \\
\hline$\ldots$. & $\ldots$. & $\ldots$. & $\ldots$. \\
\hline
\end{tabular}

In order to analyze the possible correlation between height of stored water and displacement, a scatter graphic is generated so as to guide the authors with the selection of the type of relationship existing between the two variables. The following figure shows that scatter plot.

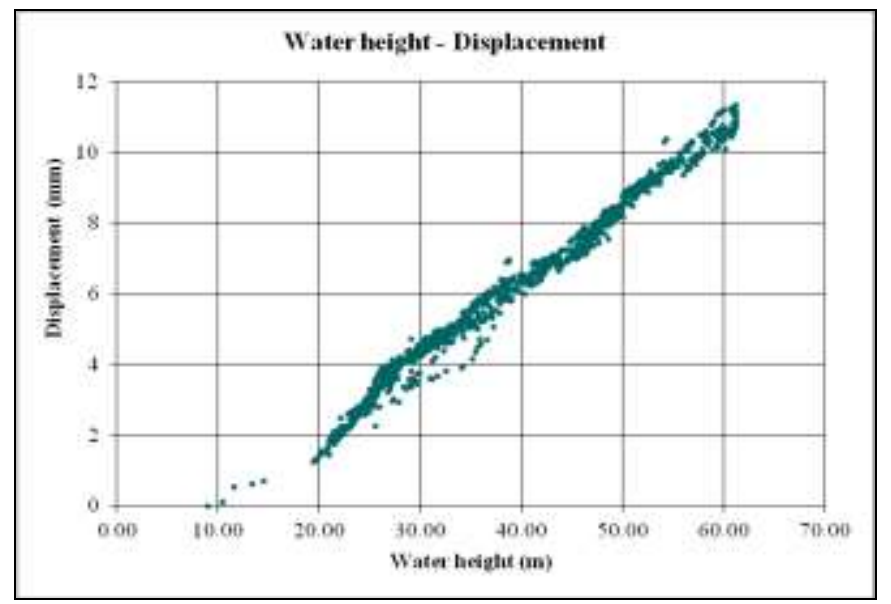

Figure 5. Scatter plot of the data.
The scatter plot above is applied to develop a Linear Regression Analysis to evaluate the relation between variables. Both in the cases of having two variables (simple regression, the situation addressed in this research) or more (multiple regression), Linear Regression Analysis is usually applied to explore the relationship between a variable called dependent, which in our case study is the displacement " $\mathrm{Y}$ ", and an independent variable, the height of store water " $X$ " here, being it all aimed to obtain an empirical equation for predictive purposes. Furthermore, regression analysis involves a series of diagnosis procedures that inform about the stability and suitability of the analysis itself.

The starting point for the development of a Linear Regression Analysis is the equation of a line:

$$
Y=a \cdot X+b
$$

Where $\mathrm{a}$ and $\mathrm{b}$ are the coefficients that determine the slope and the point at which the line crosses the axis of ordinates respectively. For its determination, it is necessary to proceed as follows:

$$
\begin{gathered}
b=Y-a \cdot X \\
a=\frac{\sum X_{i} \cdot Y_{i}-\sum X_{i} \cdot \sum Y_{i}}{n \cdot \sum X_{i}^{2}-\left(\sum X_{i}\right)^{2}}
\end{gathered}
$$

Once the equation of the line is established, certain statistical analysis that allow defining the grade of correlation between variables and the goodness of fit are carried. Among the analysis proposed, it is worth mentioning the revision of multiple correlation coefficient and its square: as there are only two variables to work with, this coefficient is the absolute value of the Pearson correlation coefficient and its square is the coefficient of determination:

$$
R^{2}=1-\frac{\text { residual sum of squares }}{\text { Total sum of squares }}
$$

This ratio expresses the proportion of variance in the dependent variable that is explained by the independent variable. Both coefficients reflect the degree of correlation existing between the variables, which is increased as their values approach to 1 , and is smaller as they tend to 0 .

It is also usual to assess the Typical Error of the Estimate (S), which is basically the standard deviation of the residuals, i.e. the standard deviation of the distances between the scores of the dependent variables and the predictions obtained from linear regression.

$$
S=\sqrt{\frac{\sum\left(Y_{i}-\hat{Y}_{i}\right)^{2}}{n-2}}
$$


In addition, a conventional Variance Analysis provides other statistics such as $\mathrm{F}$, which allows contrasting the null hypothesis that the population value of $\mathrm{R}$ is 0 , which in terms of simple regression is equivalent to test the hypothesis that the slope of the line of regression is 0 .

\section{Results}

The adjustment shown in the following figure is obtained by operating the expression presented in the previous section, with all field-observables that have been collected over the 14year period analyzed in this research:

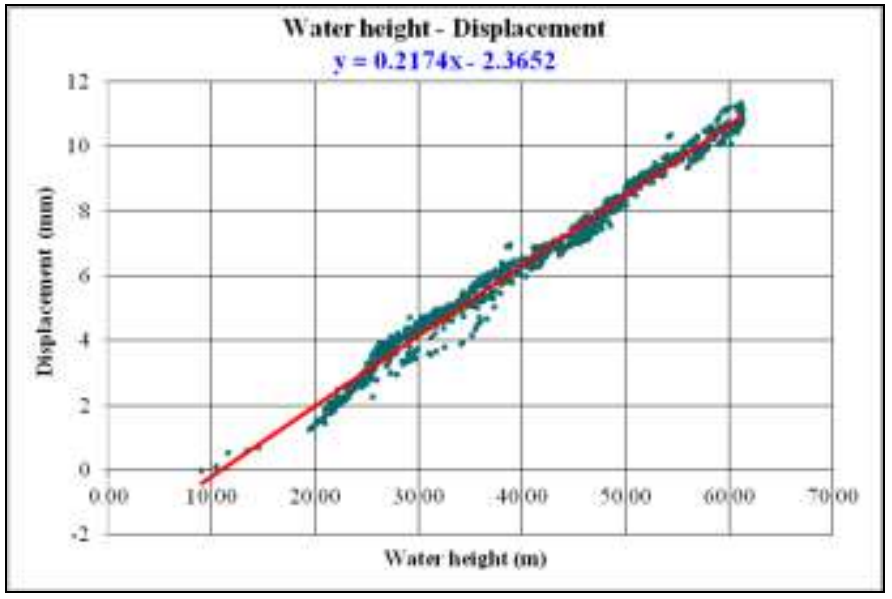

Figure 6. Results of linear regression fit.

It should be noted that the calculations were performed with a computer application, Microsoft Excel spreadsheet, due to the large number of observables considered (1242), obtaining the following expression:

$$
Y=0.2174 \cdot X-2.3652
$$

where:

$$
\begin{aligned}
& \mathrm{Y}=\text { dependent variable (displacement) } \\
& \mathrm{X}=\text { independent variable (height of stored water) }
\end{aligned}
$$

Once the adjustment has been done it is necessary to carry out the statistical analysis to determine the goodness of fit, being its most representative parameters listed in the following tables:

TABLE III. STATISTICAL ANALYSIS PARAMETERS.

\begin{tabular}{|c|c|}
\hline \multicolumn{2}{|c|}{ Regression Statistics } \\
\hline Coefficient of Multiple Correlation & 0.99342775 \\
\hline Coefficient of Determination $\mathrm{R}^{2}$ & 0,98689869 \\
\hline Adjusted $\mathrm{R}^{2}$ & 0,98688813 \\
\hline Standard error & 0,29403801 \\
\hline Number of observations & 1242 \\
\hline
\end{tabular}

TABLE IV. ANOVA RESULTS.

\begin{tabular}{|c|c|c|c|c|c|}
\hline \multicolumn{7}{|c|}{ ANOVA } \\
\hline & $\begin{array}{c}\text { Degrees of } \\
\text { freedom }\end{array}$ & $\begin{array}{c}\text { Sum of } \\
\text { squares }\end{array}$ & $\begin{array}{c}\text { Average } \\
\text { squares }\end{array}$ & F & $\begin{array}{c}\text { Critical } \\
\text { Value }\end{array}$ \\
\hline Regression & 2 & 8075.819 & 8075.819 & 93407.049 & 0 \\
\hline Residual & 1240 & 107.208 & 0.086 & & \\
\hline Total & 1242 & 8183.027 & & & \\
\hline
\end{tabular}

To complete the results it is worth mentioning that the expression obtained through linear regression adjustment was applied to the 88 observations registered during 2014, yielding an average difference between the observed value and the one provided by the analytical expression of $0.2 \mathrm{~mm}$, as it can be seen in the following table:

TABLE V. APLICATION OF ADJUSTMENT TO CONTROL OBSERVATIONS.

\begin{tabular}{|c|c|c|c|c|c|}
\hline Record & Date & $\begin{array}{c}\text { Height } \\
(\mathbf{m})\end{array}$ & $\begin{array}{c}\text { Observed } \\
\text { Displaz. } \\
(\mathbf{m m})\end{array}$ & $\begin{array}{c}\text { Empirical } \\
\text { Displaz. } \\
(\mathbf{m m})\end{array}$ & $\begin{array}{c}\text { Difference } \\
(\mathbf{m m})\end{array}$ \\
\hline 5019 & 14.01 .14 & 49.57 & 8.2068 & 8.4113 & -0.2044 \\
\hline 5020 & 17.01 .14 & 47.29 & 7.7031 & 7.9156 & -0.2125 \\
\hline 5021 & 21.01 .14 & 42.33 & 6.7597 & 6.8373 & -0.0776 \\
\hline 5022 & 24.01 .14 & 39.59 & 6.4810 & 6.2416 & 0.2393 \\
\hline 5023 & 28.01 .14 & 40.77 & 6.5663 & 6.4981 & 0.0681 \\
\hline 5024 & 31.01 .14 & 41.79 & 7.0846 & 6.7199 & 0.3647 \\
\hline$\ldots$. & $\ldots$. & $\ldots$. & $\ldots$. & $\ldots$. & $\ldots$. \\
\hline
\end{tabular}

\section{v. Discussion}

The first discussion line for the research work developed focuses on the type of regression adjustment applied. In this work, a simple correlation (single dependent variable) has been developed, considering hydrostatic thrust as the sole cause of deformation of the dam, this in detriment of other possible correlations (multi-variant analysis) in which other variables that are also related to that deformation, such as temperature, moisture, etc. could be considered. Their potential to certainly turn the state of concrete into a changing one allows considering them as related to deformation variables. These have been dismissed due to the minimum influence that they bear with respect to the hydrostatic thrust, which is clearly the most important one.

The second discussion line focuses on other possible adjustments that can be performed with a single variable, but that also allow adjusting the observed data to other curves depending on their geometry. Regarding this aspect, several adjustments to logarithmic and polynomial equations of 
degrees 2 and 3 have been performed, providing results that can be seen in the following figures:

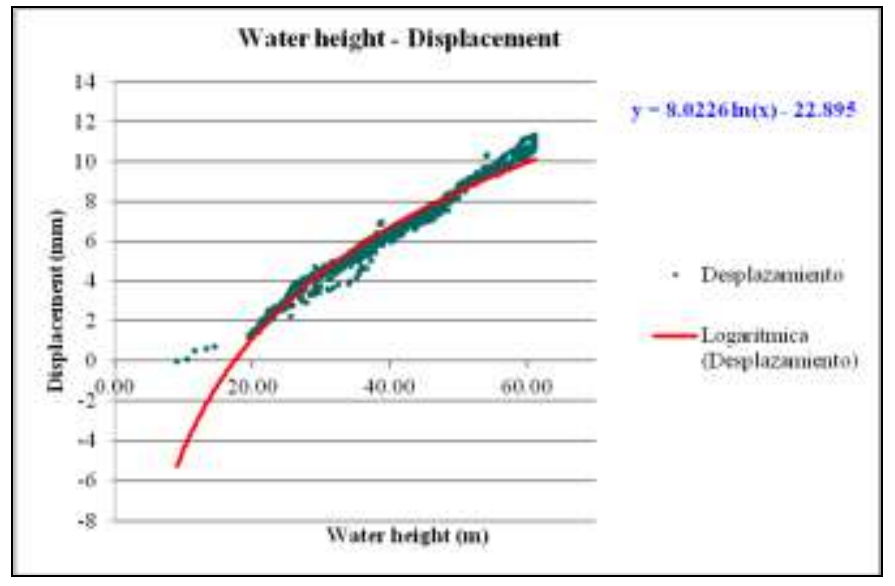

Figure 7. Logarithmic adjustment results.

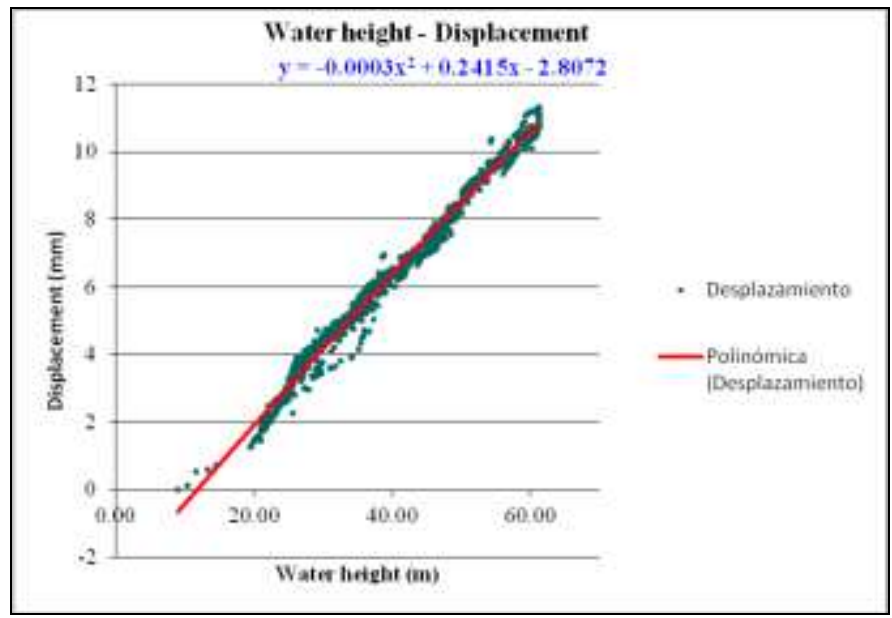

Figure 8. Polynomial adjustment results (degree 2).

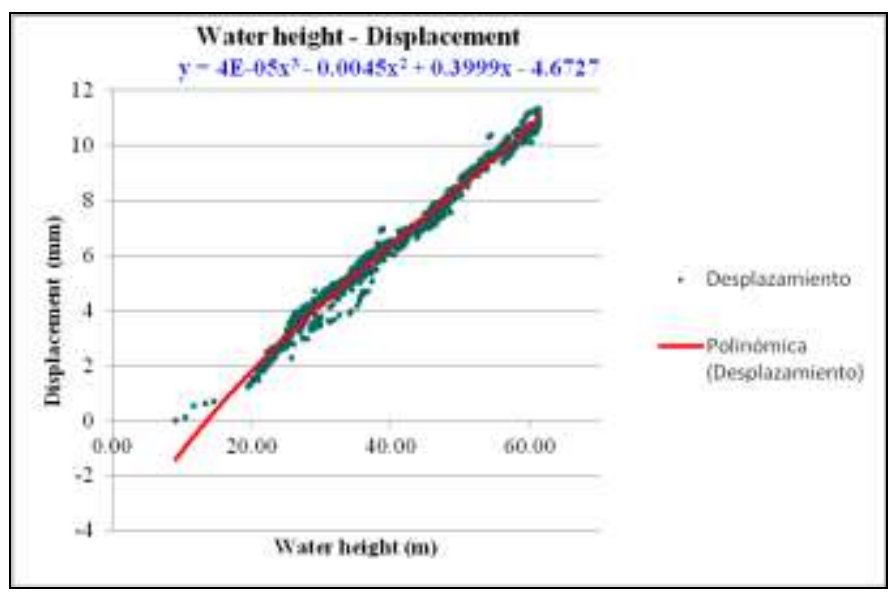

Figure 9. Polynomial adjustment results (degree 3).

It is worth mentioning that the best correlation coefficient was obtained by applying a linear adjustment, and although other options such as exponential adjustments, potential ones, etc. can be used, the distribution of observables clearly suggest a linear adjustment.

\section{vi. Conclusions}

In the light of the methodology developed, it is worth noting as main conclusion the simplicity of working with large quantities of data by means of the use of software applications, in order to establish mathematical tools with predictive character that allow the person in charge of a dam knowing beforehand the performance that the structure must develop, and even obtaining behaviour models under critical circumstances.

Taking into account results and the above exposed reasonment, it can be concluded that for the case study, after developing an expression for the calculation of the "a prior" displacement experienced by a pendulum located at the central part on top of La Cohilla Dam as a function of the height of the water stored, it is possible to contrast the beforehand obtained value with that observed in field. This allows checking the structural state of the dam, what is a worrying fact for the Management of the dam, especially under extreme conditions.

\section{Acknowledgement}

This work has been possible thanks to data supplied by the Enterprise Saltos del Nansa, which constantly supports the research that is been held by this Area of Knowledge of University of Cantabria.

\section{References}

[1] Ferrer Torio, R., et al., "Geodetic Deformation Monitoring: From Geophysical to Engineering Roles", International Association of Geodesy Symposia, Vol. 131, 2005, pp. 270-276

[2] De Luis Ruiz, J.M. "Auscultaciones geodésicas por métodos clásicos y con Láser Escáner”. Editorial Académica Española, 2012, pp. 179-184.

[3] De Luis Ruiz, J.M., Piña García, F., Pereda García, R., "Contrast between angular and distance observables in geodetic inspection of deformation". DOI: 10.15224/ 978-1-63248-030-9-59

[4] Luceño Vázquez, A., et al., "Métodos estadísticos para medir, describir y controlar la variabilidad", Editorial Universidad de Cantabria, 2005, pp.68-73.

[5] Chueca Pazos, M. et al., "Redes topográficas y locales". Servicio de Publicaciones de la Universidad Politécnica de Valencia. 1994.

[6] Fan, H., "Theory of Errors and Least Squares Adjustment". Royal Institute of Technology. Stockholm. 2005.

[7] Sevilla de Lerma, M.J., "Colocación mínimos cuadrados". IV Curso de Geodesia Superior, Instituto de Astronomía y Geofísica, Madrid, 1987.

[8] Sundakov, Y.A., "Trabajos geodésicos en la construcción de grandes obras industriales y altos edificios", Editorial Mir, 1980. 